\title{
Editorial
}

\section{TRANSFERRING THE MARGINS TO THE CENTER}

This issue presents four examples of the ways in which the presence of Latino/as is impacting various aspects of US society. Frank Barajas discusses the issue of the growing number of injunctions against gangs in California and various states in the Southwest, focusing not so much on the legal and procedural details of the injunctions, as on the political and social context in which they are implemented, as well as on the community responses and struggles against them. In so doing, he shows that the injunctions and the violence surrounding their enforcement are best understood in terms of the underlying economic interests they serve to protect, hence explaining the lack of interest by local officials in providing the structural support needed by youth who are at risk and by those actively seeking to incorporate themselves into the larger community.

Erynn Masi de Casanova's article focuses on the relationship between language and ethnic identity, taking as her point of departure the growing number of television programs aimed at mainstream audiences that incorporate Latino/a characters and use Spanish words and dialogues. She explores the various ways in which Spanish is incorporated into mainstream television and how each differentially affects the construction of the relationship between ethnicity and group identity. De Casanova discusses three different examples of this relationship, code switching, the use of bilingualism, and the homogenizing of national identities, and raises questions about implications for the socialization of both new generations of Latino/as and the mainstream at large.

Christina Sisk and Sandra Soto's essays focus on the border between Mexico and the United States from two different perspectives. Sisk analyzes articles in Mexico's Revista Generación in order to challenge the traditional link between identity formation and location, arguing that "lo mexicano as conceived from within Mexican territorial boundaries can incorporate the migrant population in the United States." In so doing, she draws our attention to the ways in which immigrants' transnational associations impact on the relationship among regional identities within Mexico and affirm deterritorialized national identities.

Sandra Soto's essay focuses on the political implications of the use of photography to discuss the ravages of poverty resulting from global economic processes and their violent consequences for people living on the border. Analyzing the border photography of Charles Bowden, she argues that while photography can and does effectively and amply demonstrate the

畒- Latino Studies 2007, 5, (391-392) (c) 2007 Palgrave Macmillan Ltd 1476-3435/07 \$30.00 www.palgrave-journals.com/lst 
tangible impact of capitalism's destructive forces, its uncritical reliance on accepted narratives of order and disorder, which have traditionally positioned tradition, community, a liberal notion of "freedom," and gender relations either as pre-capitalist or outside of capitalism, also serves to reify the culture of poverty.

Thus, although the Latino/a population experience continues to be relegated to the margins of society, as this issue suggests, its impact on the United States and beyond is increasingly apparent - whether through the ways in which Latino/as are challenging the underlying rationale of local and national laws; the cultural changes their presence is forcing in mainstream television; the realities of Latino/as' daily lives on the border, which force us to reconsider the impact of the representations of the devastating effects of globalization; or through the growing consequences of immigration on deterritorializing national identity, whether it be in the United States or in other parts of the Americas.

We are also pleased to present yet another chapter of Latino/a history in the journal's Páginas Recuperadas section, edited by Silvio Torres Saillant. This time, he focuses on the long presence of Central and South Americans in the United States.

Finally, our Vivencias: Reports from the Field section highlights an interview with the Dominican-American writer Angie Cruz, whose work provides us with yet another example of the ways in which Latino/as address and respond to the political, socio-economic, and gendered challenges they confront, even as they simultaneously affirm their multiple and (trans)national identities.

Saludos!

Suzanne Oboler

John Jay College of Criminal Justice, City University of New York, New York, NY, USA

Latino Studies (2007) 5, 391-392. doi:10.1057/palgrave.lst.8600284 